\title{
Factors Affecting Children's Satisfaction with Open Spaces with the Residential Complexes
}

\author{
Dr. Esmail Zarghami ${ }^{1}$, Engineer. Fateme Sadat Safari ${ }^{2}$ \\ ${ }^{1}$ Associate Professor of Architecture of Teacher Training martyr Rajaee University, Tehran, Iran \\ ${ }^{2}$ Architectural Graduate Student of Teacher Training martyr Rajaee University, Tehran, Iran
}

\begin{abstract}
This study examines the impact of open spaces of residential complexes in enhancing children's satisfaction. Because on one hand and according to the charts of statistics center, the number of children's society is remarkable and on the other hand, the children of this land are at same time in their cognitive development stage. House for children is like their first link and relationship with physical environment. In the first meeting of the child and this environment, their mental thoughts about the settlement are formed. Therefore, the aim of this study is to review theories and architectural approaches in relation to the open spaces of residential complexes in order to strengthen the role of these spaces in children's satisfaction and extract favorability factors of residential complexes open spaces for children. The present paper is a survey type research. The population investigated in this study consists of the parents of children living in the residential complexes of Shiraz city. To select the subjects, multi-stage cluster sampling method was used. In this regard, of the ten areas of Shiraz city, 3 areas were randomly selected. Then, of each of these areas, one residential complex was selected randomly. Finally, the sample desired was selected at random among the three complexes. In this study, the sample size required consisted of 153 people. Validity of the tool was measured by content validity method. It was recognized that the research tool had a good validity. Also, the reliability value of research too was obtained 0.89 using Cronbach's alpha. The results were investigated in spss software and using correlation and regression tests and determining direct and indirect effects of variables on children's satisfaction. The results obtained indicated that variables including open spaces, security, playability of open spaces, environmental attractions, communing with nature and access and penetrability of open spaces, in order of priority affect children's satisfaction of open spaces of residential complexes.
\end{abstract}

Keywords: residential complexes, open spaces, children's satisfaction, nature, game, flexibility

\section{Introduction}

Home is the origin and destination of human's daily life. People get out of it to go to work and social activities and return home after that and gaining experience. Home is where we come back to after experiencing different aspects of the world around. Home is of such importance that it can be called center of one's world[11]. So, home should meet the expectation of "being the center of one's world" in its internal space and exterior sight. Today, due to the life force or one-dimensional thinking and paying much attention to economy, many of human, social, native and cultural values are ignored. People get together like lumps and form a pile of individuals instead of forming positive and targeted social groups which the only result of their getting together is congestion, crowdedness and chaos. In such circumstances, to meet minimum security and peace, family members escape public and open spaces and take refuge to the corners of the houses and in the meantime, children are hurt the most. Bed is the only space that is available for children to play or just sit slightly and read. All the usual norms of homebuilding give children only some limited space and make them constantly involve with the elder's discussions and unpleasant interactions with parents which unacceptable [12]. The consequences of such a situation are the damage to the foundation of family, people and society.
However, open spaces of residential complexes are considered as inseparable parts of these buildings and public spaces especially in metropolises and play an important role in meeting citizens' social and individual needs especially children. These spaces which are used as open public spaces such as urban gardens, parks and other spaces such as schools campuses and apartment buildings as open spaces through proper design can play a vital role in the growth and strengthening of children satisfaction living in the complexes. Designing open spaces includes adults too in addition to the children who are more affected than adults and perceive the world quite different.

Children and teenagers are an important group of users of residential neighborhoods open spaces in scales of streets and alleys (neighborhood unit), local street, neighborhood center, children's garden and local parks. These spaces take up a large part of children and adolescents' daily life environment and thus improving their quality can be effective in personal growth, social interactions, strengthening a sense of cooperation and even training. Environmental interactionsin age periods of early childhood, childhood and adolescence are required for development of physical, cognitive and creative abilities of people and the individual's life environment in this period has a decisive effect on the formation of being nature and physical and mental development (Figure 1). 
International Journal of Science and Research (IJSR)

ISSN (Online): 2319-7064

Index Copernicus Value (2013): 6.14 | Impact Factor (2014): 5.611

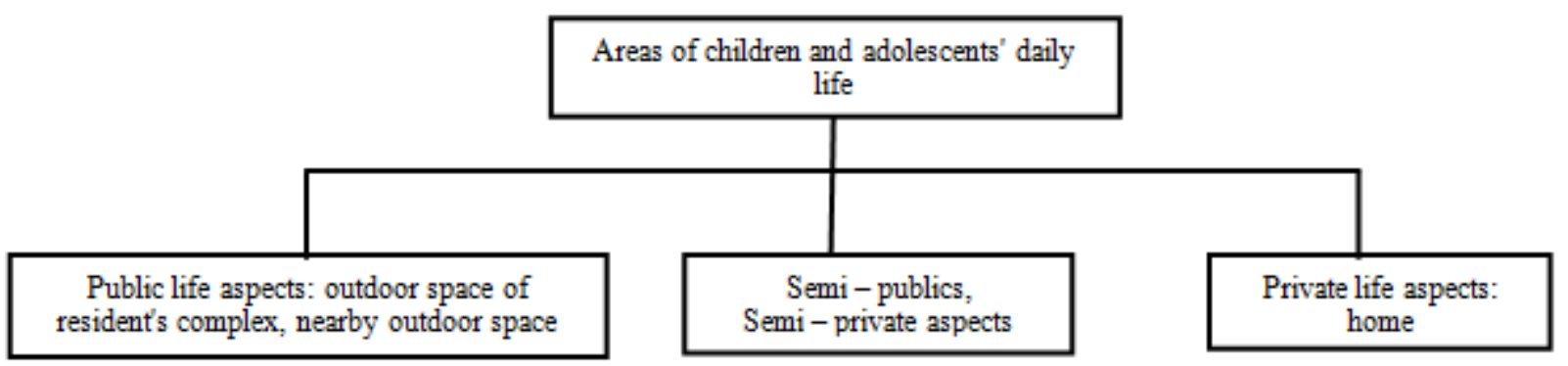

Figure 1: Areas of children and adolescents' daily life

\section{Research Problem Statement}

Neglecting children in residential complexes and their dissatisfaction of these spaces. In the present decade, we are witnessing a global worrying change in children's habits. Children now participate in free games and activities in outdoor spaces less than before and spend the majority of their time at home and extracurricular classes and under direct supervision of parents.

It seems that the time has come for concerning about the fate of children, because their situation in today's urban environments is in decline. Fear of insecurity and mismatch of cities' open spaces with children's physical and mental conditions have forced them retreat from public space towards private spaces and from neighborhoods into houses. In addition to the pressure of electronic age, this issue has threatened the innocence and purity of childhood as well as disappearance of the condition has been called "free activity" by psychologists. The consequence of this limitation is that now children are raised in some boring environments. So, instead of experiencing the environment and adventure in the world around children are searching excitements, imagination, legends and imitating TV and computer games. In this way, they are passing an "artificial childhood" created by adults.

Also, due to overpopulation and its day by day increase in large cities, some phenomenon called a lack of attention to open spaces compared to the mass has been created and this matter is a wakeup call for the disintegration of cultural structures in traditional settlements.

According to the above mentioned problems in this study, we hope to discover factors affecting children's satisfaction in residential complexes to increase their interaction with open spaces and take a small step in raising the quality of children's life.

\section{Satisfaction}

The word satisfaction is defined in the dictionary as "meeting or source of pleasure and being satisfies". It is also defined as happiness, pleasure and favorability created as a result of meeting needs and demands and requirements of client by service provider (Farhadnezahd, 2008).

Sears (1988) defines satisfaction as evaluation of one's mind from the quality of the relationship between two or more factors. He considers satisfaction based on two factors: 1. the result of a relationship, 2. someone's perception and mentality of the relationship. Sometimes, the result of a relationship is positive but we assess it negatively. Thus, it wouldn't be a satisfactory relationship for us [10]

Golester defines satisfaction as follows: satisfaction with the environment arisen from visible gap between desires and needs of the residents and the reality lying around on the context of their residence [5].

According to Inglehart, the concept of satisfaction is defined as follows: the feeling of satisfaction is created through reflecting the balance between personal wishes and objective situation.

According to Webster Dictionary, satisfaction is whatever leads to happiness, joy and gladness [13]. In Longman Dictionary, this term has been described as follows: whatever provokes desire, meeting demands and needs [8]. Cutler believes that satisfaction level is a function of difference between the perception of an individual's performance and expectations.

According to another definition, satisfaction is the happiness experienced by an individual or a member of family with their home environment [1].

\section{Research Body}

This is an applied study and it aims to develop knowledge indesigning living spaces in order to improve children satisfaction with residential complexes. Factors influencing satisfaction were identified through library studies, interviews, questionnaires and analysis and interpretation of results.

For this purpose, texts including library information and documents related to the children's satisfaction criteria were investigated and noted and after classifying and interpreting them, some constant principles were drawn. The results extracted were evaluated and thus important issues and dependent and independent variables were identified and the content of the questionnaire was formed.

\subsection{Content of the Questions}

The questionnaire contains 51 closed and multiple choice questions which was completed by subjects of the research. The questions aim to assess the impact of different variables of residential complexes open spaces on children satisfaction. Variables whose effects were questioned in this regard are:

- The quality and quantity of green spaces and the presence of natural factors in open spaces 


\section{International Journal of Science and Research (IJSR) \\ ISSN (Online): 2319-7064}

Index Copernicus Value (2013): 6.14 | Impact Factor (2014): 5.611

- Visual stimulant elements such as decomposition of natural light by glass ...

- Providing the conditions needed for gardening for children

- Flexibility and responsiveness of spaces and the possibility of involving children in arranging spaces

- The presence of elements with different uses

- Playability of open spaces and the quality and quantity of play spaces

- Creating diversity in colors and base of open spaces and avoiding monotony

- Complexity and mystery of spaces associated with children

- Appropriate access and diversity in walking routs

- The safety level of the flooring and game sites of children

- The possibility of parents control over children's sites

At the end of closed questions, respondents were asked to mention if there is another factor affecting children's satisfaction with residential complexes in their opinion. The questionnaires were distributed in number of sample size calculated which was 153 people. 136 questionnaires were completed and returned. Answers of questionnaires were loaded as follows and evaluated:

Table1: Loading the answers of questionnaires items

\begin{tabular}{|c|c|c|c|}
\hline $\begin{array}{c}\text { Very } \\
\text { much }\end{array}$ & Very & A little & $\begin{array}{l}\text { Very } \\
\text { little }\end{array}$ \\
\hline
\end{tabular}

When evaluating responses, the answers were scored as follows: $4=$ very much, $3=$ very, $2=$ a little and $1=$ very little.

\section{Population and Sample}

Population is defined as a collection of individuals or unites that have at least one common trait. In other words, population consists of all real or imagined members who we are seeking to generalize the results of research to [4]

Given the above mentioned, the population of this study consists of parents of children living in residential complexes of Shiraz city.

Sampling means selecting a number of people, events and objects of a population defined as the representative of the community. In this study, multistage cluster sampling method was used. Cluster sampling is used when selecting a group of people is more possible and easier than selecting individuals from the population defined. In the end, the complexes selected based on this sampling method are: Doustan Residential complex, Ghazal Residential complex, and Baran Residential complex.

To determine the sample size judicable during sampling, the results of similar research and assessing their statistical properties can be used according to the following equation (1) where, $S^{2}$ is the variance of study, Z: type II error of standard population distribution, and D: sample mean difference from the population mean in the whole study [3].

$$
\mathrm{N}=\frac{s^{2} e z^{2}}{d^{2}}
$$

Finally, with regard to the above mentioned and relationships, the sample sized required here is almost 153 people. With this sample size, the present study can have sufficient volume for judgment.

\section{Analysis}

\subsection{Validation of Measurement Tools}

Before analyzing data obtained from sampling, the judgment ability of this data should be measured. It means that the reinsurance capability or reliability and credibility or validity and competency of research data need to be proven. The purpose of this assessment is to investigate the accuracy and failure level of each question and to show the weaknesses, strengths and reliability of the questionnaire. To achieve this goal, first questionnaire items and target-content table were confirmed by a number of architecture experts and the relationship between subjective and content or in other words the variables obtained in respect to the content and their characteristics were examined. As a result, the validity of our tool was verified.

After this step, we must attempt to test the validity of data obtained to examine the relationship between factors and variables obtained and found a significant relationship between them using statistical analysis methods such as spss software in order to be able to provide the possibility of exploring factors in research modeling. In the present study, Cronbach's alpha method was used and the coefficient obtained was 0.892. Given that the basis and acceptable value for reinsurance coefficient is the number 7 , so 0.892 is a very satisfactory and acceptable value which implies a high validity of the questionnaire in this research. Thus, the results of the analysis have high reliability so they are considered as acceptable scientific findings.

\subsection{Identification of factors}

In the present paper, six factors (concepts) were identified through the evaluation of results derived from a literature review and interviews with experts and analyses conducted. After specifying the factors, spss software and correlation coefficient test were used to analyze the hypotheses. Then, stepwise regression analysis was done in order to evaluate which of factors creates more satisfaction. Finally, with regard to the direct and indirect relationship between variables, a theoretical model of satisfaction was presented.

- The first factor: relationship with nature

- The second factor: security

- The third factor: flexibility

- The fourth factor: playability of open spaces

- The fifth factor: environmental attraction

- The sixth factor: access and penetrability

Table2: Results of correlation test in order to examine the association between research factors and children's satisfaction \begin{tabular}{|c|c|c|c|c|c|}
\hline Variable & Mean & Standard deviation & Number & Correlation coefficient & Significance level \\
\hline
\end{tabular} 
International Journal of Science and Research (IJSR)

ISSN (Online): 2319-7064

Index Copernicus Value (2013): 6.14 | Impact Factor (2014): 5.611

\begin{tabular}{|c|c|c|c|c|c|}
\hline Relationship with nature & 3.29 & 0.34 & 136 & \multirow{2}{*}{0.869} & \multirow{2}{*}{0.000} \\
\hline Children's satisfaction & 3.26 & 0.31 & 136 & & \\
\hline Creating security & 3.34 & 0.35 & 136 & \multirow[b]{2}{*}{0.913} & \multirow{2}{*}{0.000} \\
\hline Children's satisfaction & 3.26 & 0.31 & 136 & & \\
\hline Designing flexible spaces & 3.19 & 0.36 & 136 & \multirow{2}{*}{0.906} & \multirow{2}{*}{0.000} \\
\hline Children's satisfaction & 3.26 & 0.31 & 136 & & \\
\hline Playability of open spaces & 3.21 & 0.44 & 136 & \multirow{2}{*}{0.858} & \multirow{2}{*}{0.000} \\
\hline Children's satisfaction & 3.26 & 0.31 & 136 & & \\
\hline Environmental attractions & 3.33 & 0.32 & 136 & \multirow{2}{*}{0.880} & \multirow{2}{*}{0.000} \\
\hline Children's satisfaction & 3.26 & 0.31 & 136 & & \\
\hline Access and penetrability of open spaces & 3.21 & 0.33 & 136 & \multirow[b]{2}{*}{0.881} & \multirow[b]{2}{*}{0.000} \\
\hline Children's satisfaction & 3.26 & 0.31 & 136 & & \\
\hline
\end{tabular}

According to the table above, since correlation coefficient value observed at confidence level less than $0.05(\mathrm{P}<0.01)$ is significant, so it can be stated that all the six factors introduced in the investigation and children's satisfaction are significantly and positively related. Thus, according to the data presented above, the effect of all identified factors on children's satisfaction is confirmed.

Table3: Results of stepwise regression analysis to investigate and determine factors affecting designing residential complexes open spaces on children's satisfaction

\begin{tabular}{|c|c|c|c|c|c|c|c|}
\hline Steps & Variable & $\mathrm{R}$ & $\mathrm{R}^{2}$ & $\mathrm{R}^{2} \Delta$ & $\beta$ & T calculated & Significance level \\
\hline 1 & Designing flexible spaces & 0.91 & 0.829 & 0.827 & 0.796 & 25.46 & 0 \\
\hline \multirow[b]{2}{*}{2} & Designing flexible spaces & \multirow[b]{2}{*}{0.956} & \multirow[b]{2}{*}{0.931} & \multirow[b]{2}{*}{0.93} & 0.46 & 14.72 & 0 \\
\hline & Sufficient security in open spaces & & & & 0.441 & 13.99 & 0 \\
\hline \multirow[b]{3}{*}{3} & Designing flexible spaces & \multirow[b]{3}{*}{0.982} & \multirow[b]{3}{*}{0.964} & \multirow[b]{3}{*}{0.964} & 0.361 & 14.96 & 0 \\
\hline & Sufficient security in open spaces & & & & 0.373 & 15.91 & 0 \\
\hline & Playability of open spaces & & & & 0.183 & 11.18 & 0 \\
\hline \multirow[b]{4}{*}{4} & Designing flexible spaces & \multirow[b]{4}{*}{0.992} & \multirow[b]{4}{*}{0.983} & \multirow[b]{4}{*}{0.983} & 0.265 & 14.42 & 0 \\
\hline & Sufficient security in open spaces & & & & 0.264 & 14.32 & 0 \\
\hline & Playability of open spaces & & & & 0.19 & 16.82 & 0 \\
\hline & Environmental attractions & & & & 0.247 & 12.18 & 0 \\
\hline \multirow[b]{5}{*}{5} & Designing flexible spaces & \multirow[b]{5}{*}{0.996} & \multirow[b]{5}{*}{0.992} & \multirow[b]{5}{*}{0.991} & 0.232 & 17.64 & 0 \\
\hline & Sufficient security in open spaces & & & & 0.216 & 15.8 & 0 \\
\hline & Playability of open spaces & & & & 0.18 & 22.57 & 0 \\
\hline & Environmental attractions & & & & 0.193 & 12.86 & 0 \\
\hline & Relationship with nature & & & & 0.157 & 11.61 & 0 \\
\hline
\end{tabular}

Where

$\mathrm{R}$ : the correlation between observed and predicted variables (multiple correlation coefficient)

$\mathrm{R}^{2}$ : multiple coefficient of determination

$\mathrm{R}^{2} \Delta$ : corrected $\mathrm{R}^{2}$

According to the results obtained in table above, it can be said that designing flexible open spaces has had the greatest impact on children's satisfaction. So, the share of 'designing flexible spaces" in children's satisfaction was $82.9 \%$. In the next rank, the share of "adequate security" in children's satisfaction was $10.3 \%$. In the third place, there is the "playability of open spaces" which is $3.4 \%$. The fourth place belongs to the "environmental attractions" with the share of $\beta$ : estimation (standardized coefficients)

$\mathrm{T}$ : $\mathrm{T}$ test, $\mathrm{T}$ is applied to measure coefficients significance.

Significance level of test: significance level of Student's Ttest

$1.9 \%$ and in the fifth rank there is the share of "natural elements" on children's satisfaction which was $0.8 \%$.

According to the theoretical foundations and based on the theories presented in the theoretical part, the dependent variable (children's satisfaction) is affected by the following variables:

Table 4: Path analysis

\begin{tabular}{|c|c|c|c|c|c|c|}
\hline \multirow{2}{*}{\multicolumn{2}{|c|}{ Model }} & \multicolumn{2}{|c|}{ Unstandardized Coefficients } & \multirow{2}{*}{$\frac{\text { Standardized Coefficients }}{\text { Beta }}$} & \multirow{2}{*}{$\mathrm{T}$} & \multirow{2}{*}{ Sig. } \\
\hline & & B & Std. Error & & & \\
\hline \multirow[t]{7}{*}{1} & (Constant) & $1.293 \mathrm{E}-16$ & .000 & & . & . \\
\hline & Natural factors & .167 & .000 & .184 & . & . \\
\hline & Security & .167 & .000 & .189 & . & . \\
\hline & Flexibility & .167 & .000 & .191 & . & . \\
\hline & Playability of open spaces & .167 & .000 & .233 & . & . \\
\hline & Environmental attractions & .167 & .000 & .171 & & \\
\hline & Access and penetrability & .167 & .000 & .176 & & \\
\hline
\end{tabular}




\section{International Journal of Science and Research (IJSR) \\ ISSN (Online): 2319-7064}

Index Copernicus Value (2013): 6.14 | Impact Factor (2014): 5.611

In the table above, all independent variables that have shaped the research model have been inserted into the regression program and correlation coefficient of each independent variable with dependent variable along with their significance level and effect level have been represented. As it is shown in the table above and the results of multiple regression all variable are directly correlated with the dependent variable and no variable will be deleted in this model. So, the research model will be as follows:

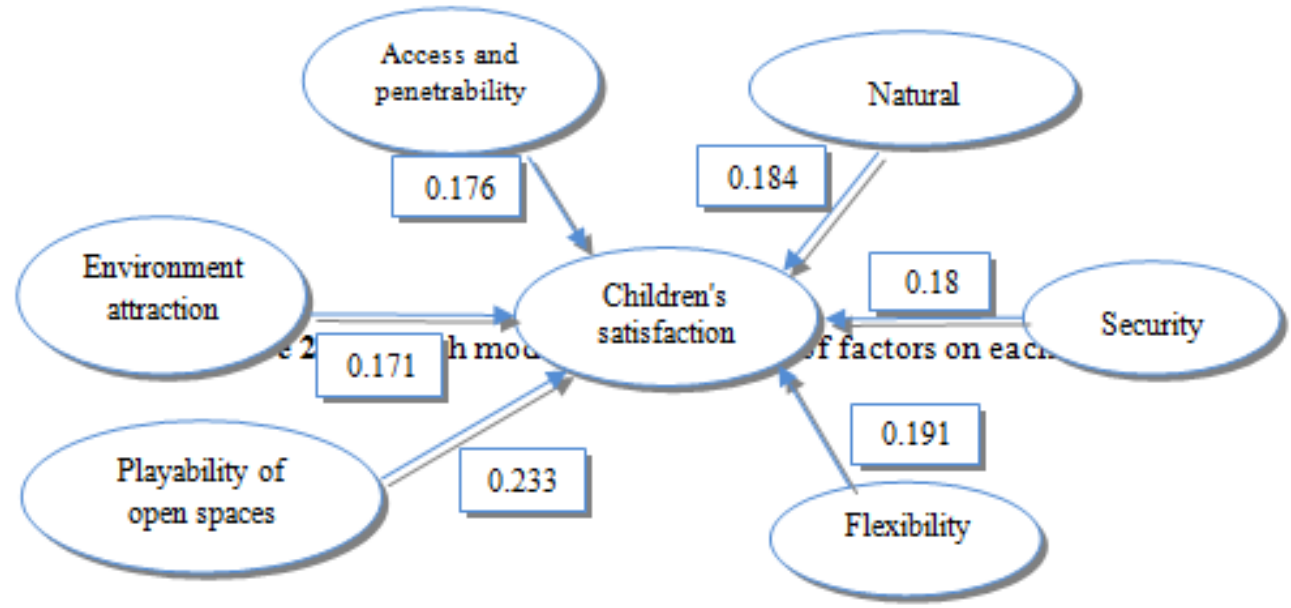

Figure 2: Research model and effect level of factors on each other

\section{Results}

\subsection{The first factor: flexibility}

Results of the present study indicate that the concept of "flexibility of open space" is the most influential factor in enhancing the satisfaction of children. Given the number of related questions (10) and also agreement of a large number of respondents, this factor was really crucial and was located in the forefront.
Flexibility acts as a mediator dependent variable and affects children's satisfaction and it itself is influenced by variables such as "the possibility of involving children in spaces layout", "dynamic and changeable spaces" and "elements with various applications". Lowering and increasing these variables affect decrease or increase of the flexibility (Figure3).

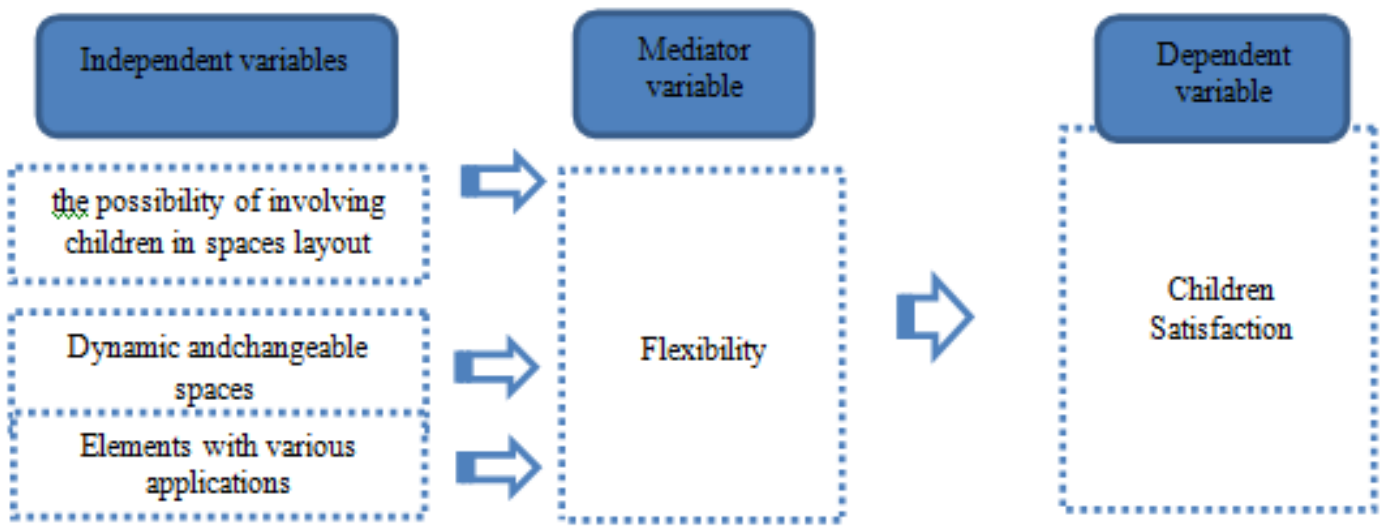

Figure 3: Graphical display of the first factor variables

Although, the architectural space is very specified and clear but for various reasons it would be needed to design a flexible space. We can consider flexibility in a system if it is possible to change the space in accordance with the desired application without destroying its main or subsidiary elements [6]. Therefore, the flexibility of operations will make it possible to use a specific space with different applications at various times simultaneously. On the other hand, flexibility can be explained as the possibility of the presence of a number of functions in the same space together and at the same time. For example, if there is a possibility to read stories or play games in a corner of a room.
Designing a flexible space with the capability of changing the components would help children to understand the layout of the living context and its adaptation in accordance with the requirements of their own practices and enhance the creative spirit of children, foster social interactions and grow the sense of participation by creating a variable space for them. Architectural ideas to design spaces to enhance children's motivation and creativity may include the variability of the space and its components, overlapping of open and closed spaces, variability and rebuilding of natural elements such as light, water and plants existed in the space. The shape and size of the space can be a ground for people's 


\section{International Journal of Science and Research (IJSR) \\ ISSN (Online): 2319-7064}

Index Copernicus Value (2013): 6.14 | Impact Factor (2014): 5.611

gathering and create a forum for interactions and social relations [7].

\subsection{The second factor: security and Safety}

According to the research carried out, the second effective factor in promoting children's satisfaction is "security". So, after flexibility, security and safety of children in open spaces and play field is of higher importance. Therefore, this concept acts as the second main factor. The variance of this factor is 10.3. Of course, like the first factor this factor is a dependent factor too which plays its role as a mediator and its independent variables include "the possibility of parent's indirect supervision over children's play spaces", no risk of collision with vehicles", safety of flooring and play equipment", "visibility of spaces and removing unsafe and hidden areas", and "safety against weather conditions (Figure4).

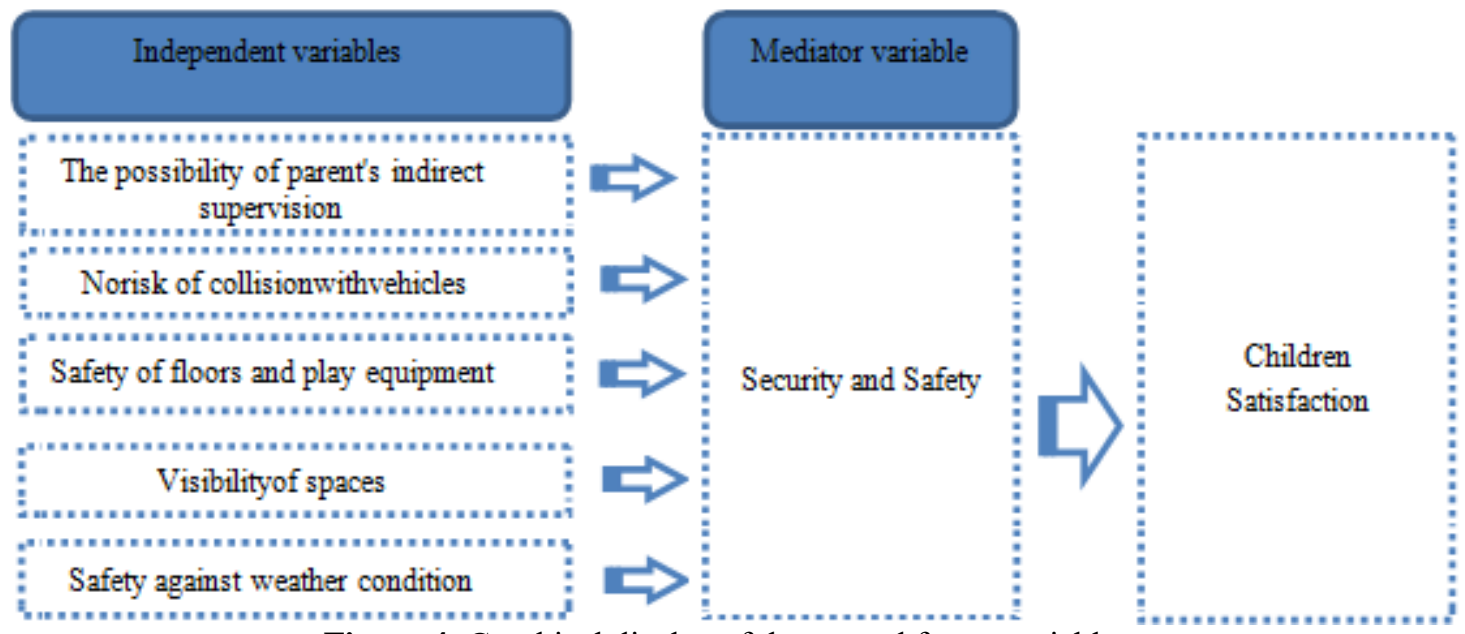

Figure 4: Graphical display of the second factor variablesr

Security is a fundamental and sustainable need which meeting other collective needs depends on its existence. In light of lack of security, satisfaction with life will be reduced which results in the loss of happiness and vitality and replacement of individual and social despair and depression.

A safe space is a familiar environment where the user feels comfortable and knows where everything is and can focus. Without such space, social relationship with others will be impossible. Because, if you don't have a space of your own, you will not be able to understand it. If we give children the opportunity to use different parts in line with their own interests, it'll participate them in affairs and a sense of belonging, thus their mental security will be met.

\subsection{The third factor: playability of open spaces}

According to the research carried out, the third effective factor in promoting children's satisfaction is the "playability of open spaces". So, after flexibility and security, playability of open spaces in residential complexes is in the third place of importance. Therefore, this concept acts as the third main factor affecting children's satisfaction. This factor is respectively obtained from the questions that measure "the quality of play space", "diversity of play equipment", and "new play equipment"(Figure5).

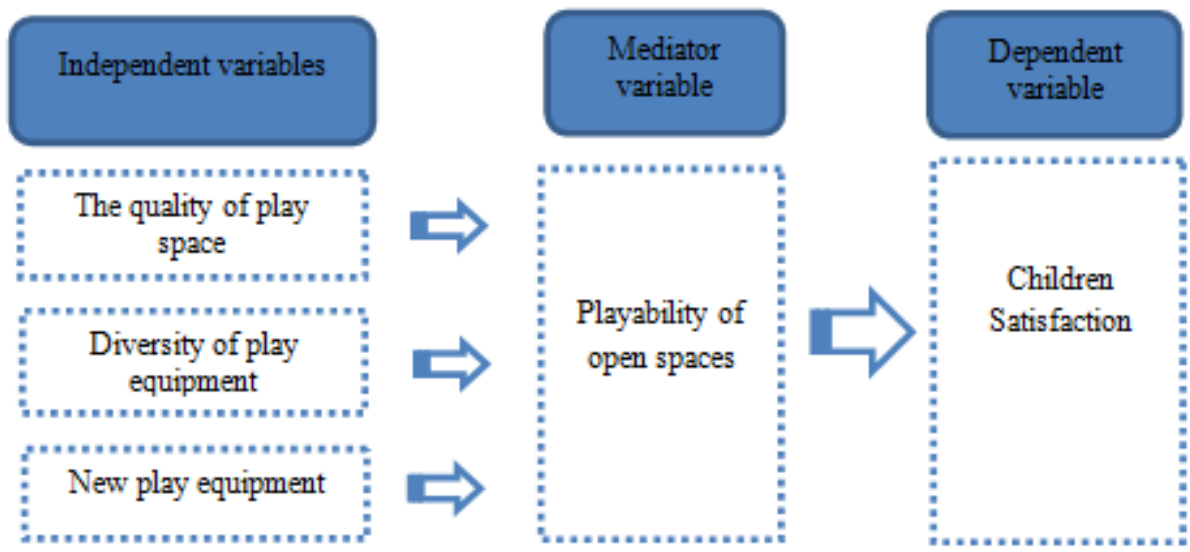

Figure5: Graphical display of the third factor variables

Playing provides the situations in which children can use their imagination, helps children relate to the outdoor environment and expand their social world, blossom their hidden talents and creativity and develop children's partnership, cooperation [9].
Playing is an instrument for child development. He learns, invent and experience through the play. Children can realize their talents, abilities, desires, weaknesses, and their pros and cons through playing and thus strengthen their personality by understanding their characteristics [9]. 


\section{International Journal of Science and Research (IJSR) \\ ISSN (Online): 2319-7064}

Index Copernicus Value (2013): 6.14 | Impact Factor (2014): 5.611

\subsection{The fourth factor: environmental attractions}

Another factor that has been extracted from the results of the questionnaires for the fourth one is named as the environmental attractions. So, after flexibility, security and playability of open spaces, environmental attractions are in the fourth place of importance. Therefore, this concept acts as the fourth main factor. This factor is respectively obtained from the questions that measure "diversity of colors and materials form", "complexity and mystery", and "creating exciting and innovative factors"(Figure6).

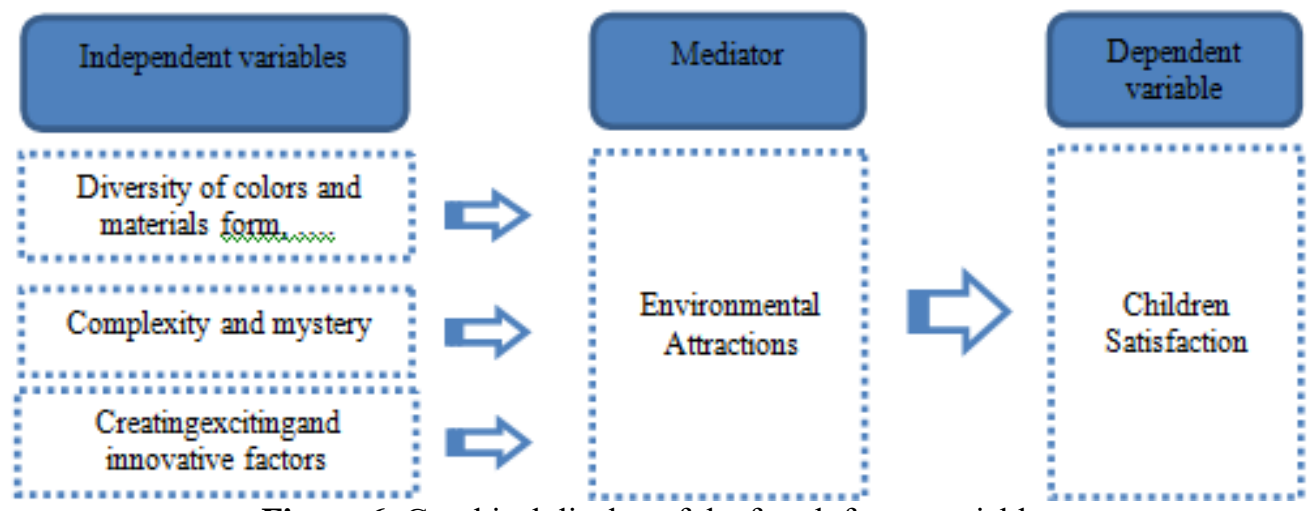

Figure 6: Graphical display of the fourth factor variables

Open spaces of residential complexes should be stimulating and engaging for children and adolescents. A balance of complexity, novelty, freshness, diversity and excitement in environments such as children's park, entrance of residential complexes, secondary routs or walking tracks and neighborhood center should make children follow the events happening in their residential environment. Otherwise, they would prefer other environments and activities that may not be in proportion to their growth. Some ambiguity, complexity and the capability of searching and discovering the hidden aspects of the environment will have a positive impact in this area.

\subsection{The fifth factor: relationship with nature}

Another factor that has been extracted from the results of the questionnaires for the fifth one is named as relationship with nature. So, after flexibility, security and playability of open spaces and environmental attractions, relationship with nature is in the fifth place of importance. Therefore, this concept acts as the fifth main factor. This factor is respectively obtained from the questions that measure "favorable green spaces", "visual motive elements", and "creating the conditions needed for planting"( Figure7).

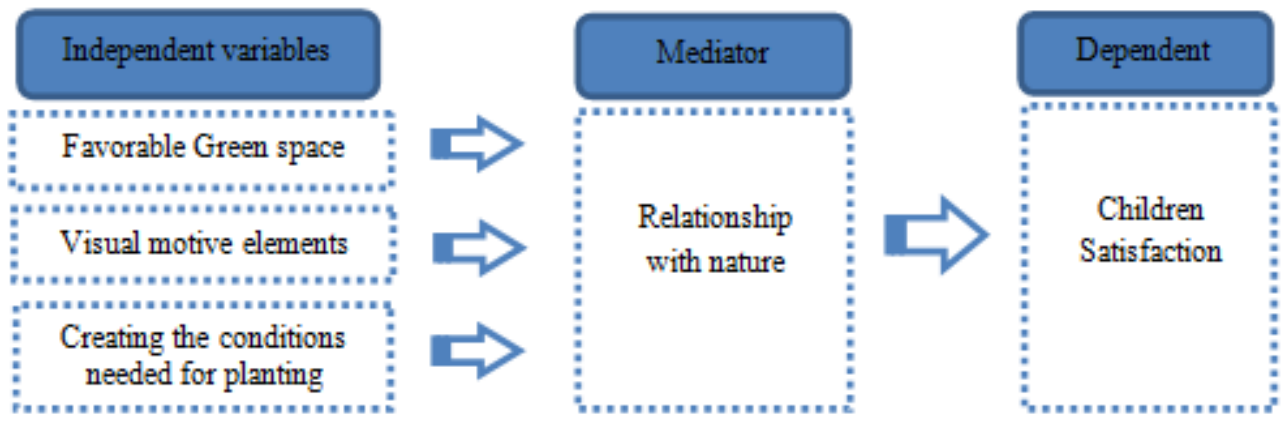

Figure 7: Graphical display of the fifth factor variables

Since children see the world around them like a kind of playground, the nature would be a suitable context that can occupy them for hours. Children feel the cold and warm of the environment on their skin, know the ground beneath their feet, hear sounds and smells around, sense the environment light with natural intensity and since they determine their movement speed, so on their own way they can understand the concepts including dimensions and distances, physical measurements as well as time dimension (Behrouzfar, 2001). Hereupon, children's ideal spaces are filled with natural elements such as plants, animals, water and soil. The reason for this matter is the three quality of natural environment that include the following:

- Endless variety

- Not being manmade
- A sense of immortality

Game facilities such as water, planting by children, playing with light and shadow through the design of space structure, playing with sand etc which are called "playability of space", not only promote children's motivation and release their emotions, but provides a good context for children's involvement in group activities.

\subsection{The sixth factor: access and penetrability of spaces}

Finally, another factor that has been extracted from the results of the questionnaires as the last factor is named as access. This factor is respectively obtained from the questions that measure "not being lost in such spaces", 
"diversity of walking routs", "units' appropriate access to the play grounds".( Figure8)

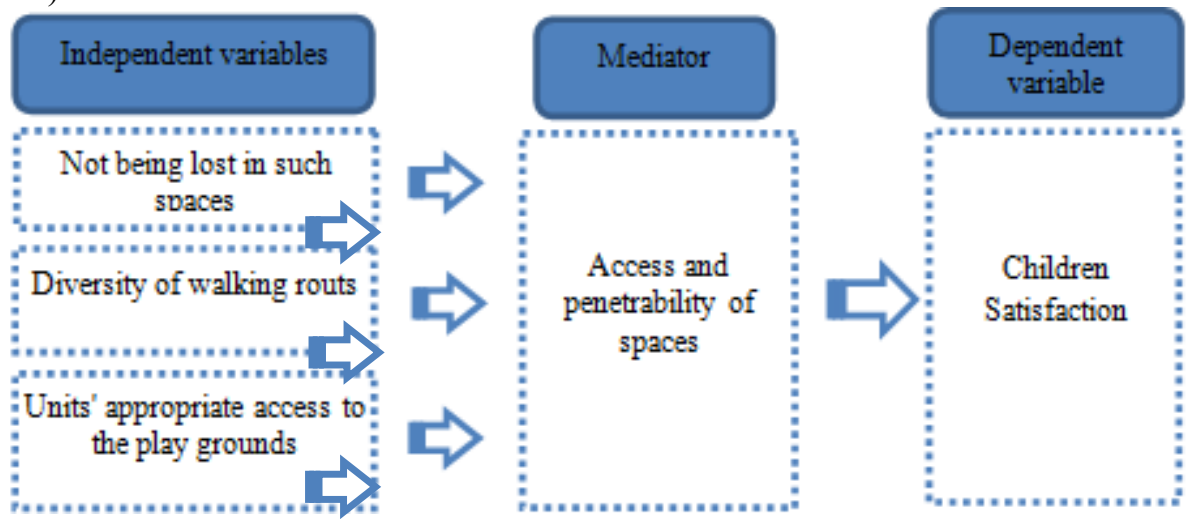

Figure 8: Graphical display of the sixth factor variables

Children's behavior in outdoor spaces is very variable and fluid and they should be able to move around in such spaces easily and without getting lost and not go out of the limitation of open spaces while discovering hidden aspects of the environment. If these spaces are designed to be impenetrable with long and tedious routs, they may discourage children from walking around in the playfield and reduce their environmental sensitivity. Children need spaces in which they are able to leave their unfinished work and resume it the next day easily and quickly. They require penetrable spaces and environments that inspire their efforts without access problem. In fact, physical activity and its continuation is not subject to a specific time or location but children need to focus, relax, and not rush in presence, passing and understanding spaces so they can use their best abilities.

\section{References}

[1] A.Annie Buchan,Evaluatingbconsumers Satisfaction With Housing, An Application Of A Systems Approach, 1974.

[2] F .Behruzfar, Basics of open spaces in residential areas, the proportion of children with mental health conditions. Tehran, Center housing construction,2002.

[3] A .Delavar, Research Methods in ethics Science \& Psychology, 28, Printing Tehran, PNU, twelfth edition, the third edition, 2009.

[4] A .Delavar, Theoretical and practical research in the humanities and social sciences, Roshd Publishers, Tehran, 2012.

[5] G .Galster,Homeowners And Neighborhood Reinvestment, Durham, Nc, Duke University Press, 1987.

[6] J. Greuther, Aesthetics in architecture, Translate by Drjahanshahpakzad\&Abdolrezahomauon, Shahidbeheshti university Publishers, Tehran, 1987.

[7] E. Hornecker. Space And Place - Setting Stage For Social Interaction, University Of Sussex. Pp. 293 - 321, 2005.

[8] Longman, Longman Dictionary Of American English, Longman,2008.

[9] S. Mahjour, The Psychology of the game, Eleventh Edition,Sasan publication, 1999.

[10]F.Mir kheshti, Investigate the relationship between marital satisfaction and mental health, Master's thesis, Roodehen Islamic Azad University,1997.
[11]C. Nuremberg Schultz, The concept of residence, Translate by Amir Yarahmadi, Agah Publishers, Tehran, 2003.

[12]R. Rodgers, Great architecture and sustainable design, Translate by Hamid Hoseinmardy, Journal of the village, Number 42, 2005.

[13] M. Webster ,Websters Dictionary Of English Usage, Merriam - WebstersInc, 1994. 